\title{
La organización deportiva y su administración de justicia en el ámbito laboral: caso ecuatoriano
}

\author{
The sports organization and its administration of justice \\ in labor disputes: Ecuadorian case
}

Favio Andrés Velasco Guevara

Investigador Jurídico, Consejo de Educación Superior (CES)

Artículo Original (Miscelánea)

RFJ, No. 4, 2018, pp. 87-106, ISSN 2588-0837

RESUMEN: el presente documento aborda la aplicación de la justicia en el fútbol a partir de la descripción de los niveles de organización deportiva y el reconocimiento que estos hacen a los métodos de solución de controversias: la justicia ordinaria laboral y los tribunales arbitrales del deporte. Con este análisis, se busca determinar la legitimidad que tiene la justicia deportiva a partir de normas de naturaleza privada para una actividad institucionalizada que genera interés público y las relaciones jurídicas que aparecen en esta actividad que se traduce en responsabilidad estatal, por lo que genera incertidumbre de las instancias competentes para conocer los conflictos de naturaleza laboral entre el jugador de fútbol (trabajador) y el club (empleador), todo esto al identificar en donde radica el reconocimiento y legitimidad para conocer estas controversias de los Tribunales de Arbitraje Deportivo, en coexistencia con la jurisdicción que ejerce el poder judicial del Estado.

PALABRAS CLAVE: fútbol, deporte, arbitraje, jurisdicción, controversias

ABSTRACT: this document describes the application of justice in football and methods of dispute resolution: ordinary labor justice and the arbitration courts of sport. With this analysis, we seek to determine the legitimacy that sports justice has and the legal relationships that appear in this activity that translates into state responsibility, which generates uncertainty of competent instance for the resolution of conflicts of labor nature between the soccer player (employee) and the club (employer), all this, when we had identified where the recognition and the legitimacy to know these disputes of the Courts of Sports Arbitration lies, in coexistence with the jurisdiction exercised by the ordinary labor justice. 
KEY WORDS: soccer, sport, arbitration, jurisdiction, controversies.

\section{INTRODUCCIÓN}

La Federación Internacional de Fútbol Asociación (FIFA), ente constituido de naturaleza puramente privada, este organismo se ha enfocado desde sus inicios en la organización y administración del fútbol a nivel mundial. Dentro de este modelo organizativo, la FIFA buscó ser parte de todos los aspectos que puedan derivarse de la práctica o de la gestión del fútbol, entre ellos, las controversias contractuales que pudieran surgir de la naturaleza laboral de la relación jurídica.

Con este fin, la justicia deportiva sufre una serie de cambios, parte de su evolución a lo largo de la historia y en todas las escalas de la organización deportiva, por lo que en el Ecuador, en observancia a los estatutos de la FIFA y al tener una federación nacional asociada a ella, se creó el Tribunal Arbitral Especial de la Federación Ecuatoriana de Fútbol mediante la Ley del Futbolista de 1958, que buscaba, entre otras cosas, institucionalizar a nivel estatal, el reconocimiento de una justicia especializada en fútbol y conflictos que surjan a partir del contrato laboral que celebra el club y el jugador profesional, conforme se desprende del artículo 37 del mencionado cuerpo normativo.

El presente texto, analiza la legitimidad de la existencia de la justicia deportiva como un procedimiento administrado por particulares para particulares desde un análisis de la organización deportiva, el reconocimiento estatal de este mecanismo de justicia y la aplicabilidad del mismo ante la existencia de normativa nacional que se contrapone a las instituciones del arbitraje como es concebida en el Ecuador y la posterior limitación para acceder a la justicia ordinaria por la concepción de dicha norma.

El planteamiento de estos temas, busca obtener una visión general de la administración de la justicia deportiva como un procedimiento privado, su coexistencia con la justicia ordinaria en un Estado de Derecho y la falta de claridad en la norma que ha generado conflicto de competencia entre la justicia ordinaria y la deportiva, dejando en indefensión a los recurrentes; y además, mostrar al lector a la consecuencia de la coexistencia de normas contradictorias. 


\section{LA ORGANIZACIÓN DEL DEPORTE}

El deporte, desde sus inicios, ha sido concebido como una actividad de recreación y esparcimiento; sin embargo, la difusión de su práctica y características ha atraído la atención y compromiso de un gran número de personas, a tal punto que hoy en día se ha constituido no solo en una actividad recomendada, sino además en una forma de desarrollo personal y profesional.

La concepción del deporte como un medio para el desarrollo humano y, actualmente, la obtención de réditos económicos, ha derivado en la creación de organismos dedicados a su difusión y organización. Tomando en consideración el crecimiento exponencial y complejo de las distintas modalidades de deportes, estas organizaciones se han visto en la obligación de generar estructuras cada vez más complejas con lineamientos mucho más organizados, lo que ha permitido que se conviertan en verdaderas instituciones del deporte.

Esta compleja forma organizativa ha sido conocida como "organización deportiva" y que se explica como "conjunto de personas que poseen intereses comunes, al menos en cuanto a la práctica, fomento, desarrollo y posibilidad de satisfacción de unas inquietudes específicas centradas en la práctica deportiva" (Álvaro, Brotons y Mestre, 2002, p.23).

La institucionalización del deporte, ha constituido una ventaja para la práctica del mismo, pero se traduce también en la aparición de nuevos actores además de los deportistas, especializados en la representación y dirección administrativa del deporte, con el que se pudo unificar los eventos deportivos generando un mayor interés colectivo en el deporte y su práctica a través de dicha organización.

En función de esto, los actores de las distintas ramas del deporte, que comparten intereses comunes, han ido desarrollado distintas formas de organización. En la actualidad, se distinguen principalmente las siguientes: 1 . Clubes deportivos 2. Asociaciones de clubes deportivos, 3. Federaciones nacionales e internacionales del deporte y 4. Estado como ente regulador. Cabe recalcar que este último no es parte de la organización deportiva como tal, pero tiene un rol importante en este ámbito. 
El Club Deportivo, es definido como "el elemento creador y dinamizador del deporte" (Álvaro, Brotons y Mestre, 2002, p.29), y considerado como el primer momento en que se fomenta la práctica de la actividad; aquí es donde el deportista se forma y compite en su representación.

A la par de la formación del club deportivo, para que este tenga legitimidad ante la ley, el Estado cumple su rol de regulador de las actividades que se realicen en su jurisdicción, por lo que en el caso ecuatoriano, el Ministerio del Deporte es el encargado del registro y reconocimiento de los clubes, pero manteniendo su naturaleza privada ${ }^{43}$.

En un segundo momento, la organización deportiva se enfocó en tener una instancia coordinadora y promotora de la práctica del deporte, por lo que las Asociaciones de clubes deportivos (o en el caso ecuatoriano asociaciones o federaciones provinciales se encargan de "la promoción de una o varias modalidades deportivas, la práctica de estas por sus asociados, así como, en su caso, la participación en actividades y competiciones deportivas") (Blanco, 2006, p.218).

A continuación, la organización deportiva, en su ámbito más amplio, se conoce como Federaciones Nacionales por deporte, que la conforman las Asociaciones y los Clubes, y la reunión de estas son las Federaciones Internacionales por deporte que según Rubén Acosta, en su obra Gestión y Administración de las Organizaciones Deportivas, las define como "las organizaciones responsables de la administración y gestión diaria de las actividades deportivas internacionales", y añade que "cada federación internacional es la autoridad mundial máxima de su respectivo deporte” (Acosta, 2005, p.30).

Es importante precisar que la organización deportiva, desde su creación, hasta sus niveles más amplios, es en general de naturaleza privada ${ }^{44}$ y que el Estado no constituye un actor directo de esta estructura, sino únicamente un regulador, lo que corrobora lo citado por Acosta al mencionar que la misma organización es el órgano máximo de regulación.

43 "La naturaleza jurídica de las asociaciones y clubes deportivos es, en la mayoría de supuestos, de tipo privado" (Blanco, 2006, p.218),

44 Debe acotarse, sin embargo, que, con la intervención Estatal a través del Ministerio de Deporte, Federaciones deportivas provinciales, cantonales, etc., el deporte si posee cierta connotación pública, por lo que su naturaleza no se restringe exclusivamente al ámbito privado, considerando además que está regulado por un ente público. 
La forma organizativa máxima del deporte a nivel mundial es el Comité Olímpico Internacional que representa el más claro ejemplo de la evolución de la organización deportiva, ya que como lo recoge $\mathrm{Ru}$ bén Acosta, el primer objetivo de esta entidad era la coordinación del evento cumbre del deporte cada cierto tiempo: los Juegos Olímpicos.

La práctica del deporte fue creciendo exponencialmente, al punto de no ser suficiente la primera estructura del Comité Olímpico Internacional, por lo que este diversificó esfuerzos y buscó reconocer a las asociaciones internacionales por deporte y que el Comité Olímpico Internacional (COI) otorgue reconocimiento y legitimidad a estas organizaciones, con el beneficio de que el deporte sea reconocido en el programa olímpico (Acosta, 2005, p.30), fortaleciendo de esta forma la estructura organizativa y manteniendo su estatus de órgano máximo y de naturaleza privada.

El énfasis en describir a la organización deportiva como un ente privado es precisamente para demostrar la legitimidad de sus instituciones, puesto que se crearon y se manejan basados en los principios de autonomía e independencia, y como muestra de ello, las mismas federaciones dispusieron instrumentos normativos propios para el efecto.

La Carta Olímpica define a las Federaciones Internacionales como un ente puramente privado y resaltando que esta organización será no gubernamental; aclara que la normativa bajo la que se rige es la que se expide jerárquicamente desde los órganos reconocidos por el Comité Olímpico Internacional según su deporte, mas no únicamente la de los Estados en los que el deporte se encuentra organizado. (Carta Olímpica, 1999, art. 29), separando definitivamente los niveles de organización.

\subsection{La Organización del Fútbol}

Conforme lo analizado, la organización deportiva tiene su ámbito internacional y representación máxima en las Federaciones Internacionales por deporte. Para efectos de este estudio, es necesario enfocar el tema en el máximo organismo que rige al fútbol a nivel mundial: para que exista legitimidad en una Federación Internacional por deporte, es necesario que esta cuente con el respaldo de las asociaciones nacionales y, por ende, que estas se encuentren asociadas a ella; es así que la Federación Internacional de Fútbol Asociación, o mejor cono- 
cido como la FIFA, por sus siglas en inglés, fue creada con el respaldo de algunas asociaciones, el 21 de mayo de 1904 y desde ese momento es reconocida por las Federaciones Nacionales, como el único organismo autorizado para representar al deporte a nivel internacional y esto se puede verificar con el paulatino ingreso de nuevos asociados a su estructura, hasta llegar a la actualidad que es la entidad internacional con el mayor número de estados asociados en el mundo (Graham y Sánchez, 2014, p.10).

\subsubsection{La FIFA, la CONMEBOL y la FEF}

El fútbol, en relativamente pocos años, se ha convertido en el deporte más popular del mundo y esto se puede evidenciar en el número de países miembros que tiene la FIFA, que, según la información entregada por el mismo organismo, son 211 Federaciones Nacionales de Fútbol adscritas a este organismo ${ }^{45}$. La distribución geográfica de los asociados a la FIFA, representó una debilidad para su trabajo, por lo cual se buscó desconcentrar su gestión, creando órganos de dirección intermedia según su ubicación en el mundo para facilitar administración, el cual recibe el nombre de Confederación.

En nuestro continente, la FIFA tiene dos entidades de organización intermedia: la Confederación de Norteamérica, Centroamérica y el Caribe de fútbol (CONCACAF) y la Confederación Sudamericana de Fútbol (CONMEBOL), que, como hemos señalado en líneas anteriores, son únicamente organismos de administración intermedia parte de la FIFA, más no una entidad regional asociada a ella (Graham y Sánchez, 2014, p.12).

Finalmente, la base de la organización internacional son las asociaciones nacionales y en el Ecuador, la Federación Ecuatoriana de Fútbol es quien asume esta representación: esta es la entidad que se conformó por la reunión de clubes y asociaciones provinciales dentro del país y es el asociado directo de la FIFA.

Ante estos niveles de organización deportiva que desde su conformación son de naturaleza privada, en cada una surge la necesidad de una instancia de resolución de conflictos, los que pueden ser de orden deportivo, disciplinario o contractual; es así como de dicha naturaleza

45 Información presentada por el portal web de la FIFA: www.fifa.com 
privada de la actividad y de la asociación que se formó a nivel nacional e internacional, se respalda que también esta instancia de justicia tenga la misma característica.

En esta premisa cabe una aclaración: como hemos revisado en líneas anteriores, desde el inicio de la organización deportiva, que es el Club, es de naturaleza privada y se basa en los principios de autonomía e independencia, por lo que en ese sentido se ha enfocado la institucionalidad de las instancias administrativas de la FIFA y tomando en cuenta que esta sociedad comprende la Federación Nacional con la Federación Internacional (en este caso la FEF se asocia con la FIFA) y que la CONMEBOL constituye un ente administrativo, en estas dos instancias es donde se legitima la aplicación de la justicia deportiva.

Si bien es cierto, la CONMEBOL maneja también su instancia de justicia deportiva, pero al ser un órgano de administración intermedia de la FIFA, no es una instancia necesaria para conocer conflictos que se presenten en las asociaciones nacionales, sino únicamente resuelven problemas que suceden en las competiciones organizadas por esta.

Ante este análisis de las instituciones, podemos determinar que la organización deportiva nace con la intención de ser un órgano de gestión, pero dadas las necesidades que presentaban los asociados, debía ejercer funciones de administrador de justicia, por lo que la justicia deportiva nace como un factor especializado en resolver conflictos en el deporte y esta autotutela se legitima en la especialización que este tipo de justicia debe tener para resolver conflictos oportunamente según la esencia de la actividad, en la autonomía e independencia de las organizaciones y en la naturaleza tanto del deporte, como de la organización, que es privada.

\section{LA JUSTICIA DEPORTIVA}

El deporte tiene dos ámbitos de justicia para lo que se dispone de instancias específicas que lo regulen: 1 . Las reglas de la práctica del deporte, para lo cual, los árbitros de la disputa deportiva en específico, son los encargados de impartir justicia en el desarrollo de la actividad, y 2. En el ámbito externo a la práctica del deporte, que se encargan de la resolución de los conflictos que lo rodean, incluido en lo disciplinario y los Tribunales de Justicia deportiva. 
Este estudio se enfocará en analizar el segundo ámbito de la justicia deportiva, en razón de el régimen especial que constituye la existencia de una instancia de resolución de conflictos específica por la materia, reconocida por la organización, de naturaleza privada, pero con independencia y autonomía de esta.

Al respecto, Norberto Outerelo se refiere a la justicia deportiva, la describe como "(...) quien se ocupa de dirimir los conflictos y controversias que se generan en el mundo del deporte, que tienen que ver con él y con los sujetos que lo comprenden. Este mundo del deporte está compuesto no solo por los conflictos que se suscitan en la práctica del mismo, sino que abarca toda la problemática civil, comercial, laboral, penal, etc. (....)" (Outerelo, 2009, p. 20).

En este sentido, la justicia deportiva, al igual que la organización deportiva, tiene dos niveles fundamentales de estructura: nacional e internacional; por lo tanto, se configura una suerte de doble instancia de juzgamiento entendido desde la independencia que tiene la justicia deportiva nacional como internacional. En el caso ecuatoriano, la FEF tiene un Tribunal de Justicia propio y la FIFA reconoce al Tribunal de arbitraje deportivo "TAS", por sus siglas en francés (Tribunal Arbitral du Sport), como su instancia competente, plasmándose así la doble instancia.

Cabe destacar que la jurisdicción que ejerce un determinado Tribunal de Justicia depende de en qué ámbito se desarrolla el conflicto, por ejemplo: en el caso de que un conflicto sea contractual, la primera instancia para sustanciar esta controversia será el Tribunal de Justicia de la Federación Nacional, en razón que es el ente al que el club debe acudir para registrar estos actos y tener legitimidad ante la FIFA, pero si un club participa en un torneo de su Confederación, y el conflicto tiene que ver con ese certamen en específico y la actuación de las partes en él, la primera instancia sería en este organismo, que como se había señalado anteriormente, se ocupa de los conflictos de sus torneos en específico; en ambos casos la segunda y última instancia de justicia deportiva es el Tribunal Arbitral du Sport, al cual nos referiremos más adelante.

En el ejemplo anterior, se debe aclarar que, si el conflicto es de naturaleza contractual, no podría ser conocido por el Tribunal de Justicia de la Confederación porque esta únicamente funge como receptora de esta información por parte de la Federación Nacional, lo que limita su competencia a los eventos de orden disciplinario que se presenten en el desarrollo de sus torneos. 
Es importante señalar que las organizaciones deportivas desarrollan sus actividades en una jurisdicción determinada, por lo que el Estado como forma organizativa de una nación, tiene la obligación social de verificar y validar las acciones que la administración de justicia deportiva impartida por la organización, por lo que debe reconocer la naturaleza privada de la federación nacional, sin separarse de la responsabilidad que tiene como Estado de garantizar los derechos de los ciudadanos, como es el libre acceso a la justicia, la tutela judicial efectiva y los demás principios generales del Derecho.

\subsection{El Tribunal Arbitral du Sport (TAS) y su reconocimiento por parte de la FIFA}

En 1984, Juan Antonio Samarach, Presidente del Comité Olímpico Internacional de ese entonces, promovió la creación del Tribunal Arbitral du Sport (TAS), en búsqueda de consolidar una jurisdicción especial para la resolución de conflictos en el deporte, al cual le otorgó total independencia del órgano rector del deporte para garantizar el principio de imparcialidad (Rosero, 2017, p.34).

La FIFA, como órgano máximo de administración del fútbol, ofertó soluciones para las controversias de sus asociados desde su creación en el año 1904 hasta el año 2002, cuando el TAS fue reconocido por esta Federación Internacional como medio de resolución de disputas en respuesta a la falta de capacidad para administrar la justicia deportiva por la misma FIFA; todo esto se consolida en el Congreso Extraordinario de la FIFA de Buenos Aires en 2001, en el cual se encargó a la FIFA crear un tribunal de arbitraje para el fútbol, por lo que se creó la Cámara Internacional de Arbitraje Futbolístico, que posteriormente sería remplazado tras el reconocimiento del Tribunal Arbitral du Sport como instancia máxima de resolución de disputas (Echeverría, s/f, p.92). El órgano de administración de justicia en el fútbol fue creado, pero al no tener el suficiente financiamiento para mantenerlo, la FIFA, como parte del Comité Olímpico Internacional, a través del Consejo Internacional de Arbitraje Deportivo ${ }^{46}$ (ICAS), fundación a cargo de gestionar el TAS, reconoció a esta instancia de solución de disputas como la entidad de administración de justicia oficial de la FIFA (Echeverría, s/f, p.92).

46 Organismo autónomo e independiente de la organización deportiva (FIFA) pero reconocido por ella directamente y a través de su pertenencia al Comité Olímpico Internacional, que lo legitimó previamente con la iniciativa de Juan Antonio Samarach. 
Como parte de la institucionalidad de la FIFA, dentro de sus estatutos se prevé, en su capítulo IX, al arbitraje como método de resolución de las disputas que pudiesen existir en el fútbol y reconoció al Tribunal Arbitral du Sport como órgano habilitado para resolver disputas en este deporte (Estatuto de la FIFA, 2016, Cap. IX).

El Tribunal Arbitral du Sport, es un órgano autónomo e independiente de la organización deportiva, pero reconocido por ella, al cual se puede acudir en caso de disputas de naturaleza comercial y disciplinaria y se maneja con las características básicas de la institución jurídica del arbitraje como método alternativo de solución de conflictos, y como tal, para acceder a él, se debe contar con la aceptación de someterse a dicha jurisdicción (Echeverría, s/f, p.93).

Existen dos procedimientos que maneja el TAS para la resolución de conflictos: el ordinario y el de apelación (Rosero, 2017, p.35), y para acceder a cada uno de ellos, el consentimiento debe plasmarse en diferentes momentos: en el caso del procedimiento ordinario, la aceptación de someterse a la jurisdicción del TAS debe ser recogida por una cláusula del contrato o en un documento posterior a la celebración del mismo y que este sea suscrito por las partes; en tanto que para el procedimiento de apelación, el consentimiento se consagra dentro de los estatutos de los órganos o federaciones al que se encuentran adscritas las partes en disputa, puesto que la normativa FIFA exige el reconocimiento al Tribunal Arbitral du Sport como instancia para resolver las controversias para pertenecer a ella (Estatuto FIFA, 2016, Art.11.4.c).

Además, el Tribunal Arbitral du Sport tiene la característica de fungir como última instancia, dado que el Estatuto de la FIFA señala que ejerce jurisdicción una vez se hayan agotado los momentos previos que reconozca el Estatuto de la organización respectiva en cuestión, es decir, tal cual sucede en el caso de la FEF, establece que las controversias de los asociados deben ventilarse ante el Tribunal Arbitral Especial de la FEF, y en ese sentido, el TAS no sería competente de analizar un recurso ante un acto ejecutado en Ecuador si no es previamente conocido por el Tribunal de la Federación Ecuatoriana de Fútbol, como lo abordaremos más adelante (Estatuto FIFA, 2016, Art.67.2)

Es fundamental distinguir dos momentos en el que se legitima la existencia del TAS y son cuando la FIFA (y en consecuencia las Federaciones Nacionales asociadas a ella) le otorga su reconocimiento como lo hemos verificado tras este análisis, y cuando los Estados pre- 
vén su existencia a través de las organizaciones deportivas como entidad capaz de impartir justicia en su jurisdicción territorial.

Ante la aparente jurisdicción absoluta que ejerce el Tribunal Arbitral du Sport para conocer disputas en el fútbol, existe una excepción: las resoluciones que emitidas por el TAS tienen sujeción a la normativa que disponga y reconozca la FIFA y de manera complementaria el derecho suizo, y dentro de las normas FIFA, se encuentra el Reglamento del Estatuto y Transferencia de Jugadores, el cual, en su artículo 22, prevé la posibilidad que un club o un jugador, en materia de disputas laborales, puedan acudir a la justicia ordinaria, reconociendo así a la tutela judicial efectiva estatal en controversias laborales sin que contravenga la reglamentación FIFA, puesto que es un cuerpo normativo de la misma organización la que reconoce esta jurisdicción (Reglamento del Estatuto y la Transferencia de Jugadores, 2018, Art. 22).

De esta forma, determinamos que la competencia la justicia deportiva es producto de un acuerdo previo a la asociación de las federaciones nacionales de fútbol a la FIFA, con el fin de ser reconocidos por ella, en tanto que el rol estatal en la administración de justicia se legitima tras la posibilidad que abre la FIFA, a través de su Reglamento del Estatuto y la Transferencia de Jugadores, de que se conozcan las controversias laborales por parte de la justicia ordinaria, sin contravenir su normativa y dejando la decisión de la instancia competente a los recurrentes.

\section{FUNCIONAMIENTO DE JUSTICIA EN EL FÚTBOL ECUATORIANO}

Como hemos detallado en párrafos anteriores, el órgano máximo de organización deportiva en el fútbol ecuatoriano es la Federación Ecuatoriana de Fútbol, entidad de derecho privado y autónomo, que organiza y administra la práctica profesional del deporte y dentro de los estatutos de esta organización deportiva, se prevén instancias específicas para cada aspecto de la gestión que esta entidad debe realizar. dentro de estas se encuentra el aspecto disciplinario como parte de los temas que regula la FEF.

A su vez, al ser el Ministerio del Deporte la cartera de Estado encargada del registro de los clubes y asociaciones deportivas, este es el responsable de aprobar los estatutos de la Federación Ecuatoriana de 
Fútbol y como representante del Estado en este ámbito de naturaleza privada, aboga por el respeto a la normativa nacional.

Es por esto que en el mencionado Estatuto que se encuentra vigente, al referirse a las competencias del Tribunal Arbitral Especial de la FEF, menciona que los litigios deportivos que se pudieren presentar en el fútbol ecuatoriano, tienen que ser conocidos por esta instancia, (que dicho sea de paso reconoce que esta normativa debe tener sujeción normativa y constitucional) sin perjuicio de lo que disponga la demás normativa aplicable para el efecto, como las normas especiales de la FEF o de la FIFA (Estatuto de la FEF, 2016, art. 87).

Con estos antecedentes, podemos determinar que la justicia en el fútbol ecuatoriano tiene dos ámbitos: el de la justicia deportiva que emane del Tribunal Especial de la FEF y el de la justicia ordinaria reconocida por la normativa FIFA, específicamente en el Reglamento sobre el Estatuto y Transferencia de Jugadores y tácitamente por el Estatuto de la Federación Ecuatoriana de Fútbol aprobado por el Ministerio del Deporte.

\subsection{Tribunal Arbitral Especial de la FEF}

El arbitraje como institución jurídica, es un método alternativo de solución de conflictos de naturaleza voluntaria, tal como lo recoge la legislación ecuatoriana vigente (Ley de Arbitraje y Mediación, 2006, art. 6), por lo cual, al ser precisamente "alternativo", para ser reconocido debe contar con la declaración de voluntad de las partes de someterse al mismo.

Como lo hemos mencionado en párrafos anteriores, la aceptación del sometimiento a esta jurisdicción por parte de la Federación Ecuatoriana de Fútbol y por consiguiente de sus asociados, radica en la sola afiliación a la FIFA, en razón que sus estatutos prevén a este medio como el legítimo para resolver las controversias, independientemente que si los contratos de la federación con los clubes así lo contemplen.

Por esto, y en búsqueda de plasmar la autonomía del deporte y de la organización deportiva, la Federación Ecuatoriana de Fútbol creó su Tribunal Arbitral, con el fin de que sea la instancia que conozca las controversias que se presenten con sus asociados, que a su vez es reconocido por la FIFA, a la par que el máximo órgano de administración 
de justicia en el deporte, que es el TAS, puede declararse incompetente para conocer alguna controversia que no haya agotado instancias previas previstas en los estatutos y reglamentos de la federación en controversia, por lo tanto, al contemplar al Tribunal Arbitral como la instancia prevista en el Estatuto de la FEF para la resolución de los conflictos, mientras este no lo resuelva, el TAS no ejercería jurisdicción para conocer la controversia.

Paralelamente a esto, como se dijo anteriormente, en controversias laborales, la normativa de la FIFA abre la posibilidad a que se pueda acceder a la justicia ordinaria de cada Estado, por lo cual, el Tribunal Arbitral de la FEF no constituye la única y exclusiva instancia para resolver los conflictos laborales, sino que deja en manos de los accionantes el acudir a la justicia por cualquiera de estos dos medios (Reglamento del Estatuto y la Transferencia de Jugadores, 2018, Art. 22).

Asimismo, como parte de la relación jurídica que existe entre las organizaciones deportivas y el Estado, este reconoce mediante ley la existencia y legitimidad del Tribunal Arbitral Especial de la Federación Ecuatoriana de Fútbol, lo cual se analizará más adelante.

\subsection{Art. 37 de la Ley del Futbolista}

En función del mencionado rol que el Estado tiene en la organización deportiva, el legislador ecuatoriano consagró mediante ley el régimen jurídico en el que se desenvuelve el jugador profesional de fútbol y para el efecto expidió en el año 1994 la Ley del Futbolista.

Dentro de los aspectos que aborda este cuerpo normativo, analiza la relación laboral que existe entre los futbolistas profesionales y el club en el que prestan sus servicios, lo cual se perfecciona con la existencia del contrato celebrado entre ellos. Así lo define el artículo 1 de la Ley del Futbolista Profesional, "se entenderá por futbolista profesional al deportista que, habiendo celebrado un contrato escrito con un club afiliado a la Federación Ecuatoriana de Fútbol, además de la reposición de los gastos necesarios para el desarrollo de sus actividades, también percibiere una remuneración periódica." (Ley 56, 1994).

Ante la naciente relación jurídica laboral en razón del contrato de trabajo, la Ley del Futbolista prevé la existencia de conflictos y se des- 
cribe como una competencia exclusiva para solventar dichas disputas al Tribunal Arbitral Especial de la FEF.

El artículo 37 de la LFP señala lo siguiente en referencia a la solución de conflictos:

\section{De las contravenciones}

Art. 37. En caso de conflicto derivado del cumplimiento del contrato, el club y el futbolista profesional deberán recurrir obligatoria y previamente al Tribunal Arbitral Especial de la Federación Ecuatoriana de Fútbol, de acuerdo con lo prescrito por sus estatutos y reglamentos.

La resolución definitiva del Tribunal Arbitral Especial de la Federación Ecuatoriana de Fútbol deberá ser adoptada en el plazo máximo de quince días, contado a partir de la presentación del correspondiente reclamo.

Si subsistiere el conflicto, por falta de acuerdo, las partes podrán recurrir a defender sus derechos ante las autoridades y jueces competentes."(Ley 56, 1994, art. 37)

De esto se desprende la existencia de un Tribunal Arbitral especializado para este tipo de conflictos, pero presenta algunas particularidades que llaman la atención en este artículo, tales como la obligatoriedad que sugiere el someterse a este Tribunal como paso previo al conocimiento de la justicia ordinaria del caso en particular, vulnerando los derechos de protección consagrados en el artículo 75 de la Constitución de la República del Ecuador ${ }^{47}$.

\subsection{Análisis normativo de competencia, implicaciones y aplicabilidad.}

Por las características que tiene la actividad del futbolista profesional, el acceso a la justicia debe ser mucho más ágil que la justicia ordi-

47 "Art. 75. Toda persona tiene derecho al acceso gratuito a la justicia y a la tutela efectiva, imparcial y expedita de sus derechos e intereses, con sujeción a los principios de inmediación y celeridad; en ningún caso quedará en indefensión. El incumplimiento de las resoluciones judiciales será sancionado por la ley" 
naria, pues no existe el mismo nivel de "estabilidad laboral" en cuanto al futbolista, además del período de actividad (en cuanto a años de carrera profesional) que tiene en relación con los otros oficios. Con estas premisas se prevé un mecanismo especializado para la solución de conflictos en materia laboral deportiva que es el Arbitraje Deportivo, pero, a la luz del cuerpo legal especial para solventar esos conflictos, que es la Ley de Arbitraje y Mediación, se evidencian ciertas situaciones que no quedan claras.

A pesar que la expresión de voluntad de someterse al procedimiento arbitral se configura en un momento previo por parte de los clubes y asociaciones (en los Estatutos), dejamos de lado que el consentimiento tiene que ser de las dos partes de la relación laboral, tomando en cuenta que quien aceptó someterse a estos medios alternativos de solución de conflictos fueron los asociados, es decir el Club y la Federación, pero el jugador constituye un sujeto de derechos distinto a los dos primeros, además de su condición de persona, ciudadano y trabajador; por lo que tiene derecho a acceder a la tutela judicial efectiva para defender sus derechos y de no expresarse esta voluntariedad en el contrato que se celebra con el club o la asociación, o bien su íntegro respeto a los Estatutos (lo que incluye el sometimiento a la justicia arbitral), la norma estaría dando el carácter de obligatorio al Arbitraje, lo que va en contra de la Ley de Arbitraje y Mediación ${ }^{48}$.

Además del parámetro del consentimiento para someter la controversia al Arbitraje, el hecho que el artículo 37 de la Ley del Futbolista Profesional contemple a este método de solución de conflictos como paso previo para acceder a la justicia vulnera la Constitución de la República del Ecuador, específicamente a la tutela judicial efectiva puesto que no se prevé un camino expedito para acceder a la justicia ordinaria, en razón que el mencionado artículo de la ley del futbolista sugiere la obligatoriedad de someter la controversia al Tribunal Arbitral Especial de la FEF de manera previa al conocimiento de la justicia ordinaria.

En otro inciso del mismo artículo 37, se le da una potestad coercitiva al Tribunal Arbitral de la FEF, es decir, le da la capacidad de ejecutar

48 "Art. 1. El sistema arbitral es un mecanismo alternativo de solución de conflictos al cual las partes pueden someter de mutuo acuerdo, las controversias susceptibles de transacción, existentes o futuras para que sean resueltas por los tribunales de arbitraje administrado o por árbitros independientes que se conformaren para conocer dichas controversias." (el resaltado me pertenece). 
las decisiones arbitrales, cuestión que, por la naturaleza del método alternativo de solución de conflictos, no va de la mano, puesto que en el artículo 32 de la Ley de Arbitraje y Mediación otorga la potestad de ejecución a la justicia ordinaria (Codificación 14, 2006, Art. 32), lo que tiene concordancia con el Código Orgánico General de Procesos (COGEP), que en su artículo 363 enumera los títulos de ejecución (requisito necesario para someter la controversia a un proceso de ejecución) y dentro de ella menciona a los laudos arbitrales.

El hecho que se le otorgue la capacidad de ejecutar las decisiones al Tribunal Arbitral Especial de la FEF puede dejar en indefensión al que resulte afectado con la resolución que contenga el laudo, puesto que la presentación del proceso ante la justicia ordinaria no le da un efecto suspensivo al laudo en el caso de la apelación ante la justicia deportiva, pudiendo haberse vulnerado los derechos y sin garantizar aún el acceso a la justicia ordinaria (Estatuto FIFA, 2016, Art.58.4).

De este análisis nace cuestionar al respecto que sí existe verdadera jurisdicción por parte de la justicia ordinaria en el derecho deportivo en materia laboral tal como lo concibe la Ley del Futbolista, situación que no pasa dentro de la normativa deportiva que claramente reconoce tanto a los tribunales arbitrales de las federaciones parte de la FIFA así como la posibilidad que se acuda a la justicia ordinaria para el efecto.

En este sentido, el problema no son las instituciones de la justicia deportiva, la norma FIFA o su reconocimiento a la posibilidad de acceder a la justicia ordinaria en controversias laborales, sino la forma como se concibe al Tribunal Arbitral Especial de la FEF por parte de la Ley del Futbolista, que desnaturaliza la institución del arbitraje y evita el libre acceso a la justicia ordinaria en caso de así considerarlo, puesto que dicha redacción ha ocasionado que la Corte Nacional de Justicia se pronuncie respecto a lo que dispone el artículo 37, como un prerrequisito para el acceso a la justicia ordinaria el someter la controversia a la jurisdicción del Tribunal Arbitral, tal como lo desarrolla en su considerando sexto el Recurso de Casación 299 de 10 de octubre de $2002^{49}$.

En conclusión, es totalmente legítima la existencia de la justicia deportiva como se ha descrito en párrafos previos, así como el TAS o el Tribunal Arbitral Especial de la FEF; sin embargo, al existir una norma nacional que señale expresamente que obligatoriamente se tiene

49 Juicio de trabajo que siguió Carlos Díaz en contra de Barcelona Sporting Club. 
que ventilar una controversia en el Tribunal de forma previa a acceder a la justicia ordinaria, ha ocasionado que los jueces ordinarios se inhiban por incompetencia, generando graves vulneraciones de derechos y la necesidad urgente de modificar este artículo y permitir que en materia laboral el recurrente pueda optar sea por la justicia deportiva como la justicia ordinaria, que son reconocidas tanto por el Estado ecuatoriano como por la FIFA y que coexisten perfectamente de no ser por el análisis de la norma que hemos realizado.

\section{CONCLUSIONES}

En síntesis, la justicia deportiva tiene total legitimidad tanto en la organización deportiva por la naturaleza privada de la estructura organizativa como tal y de la práctica del deporte y por ser un método aplicable y viable para la resolución de conflictos por lo que implica la actividad laboral "sui generis" que representa el ser futbolista, por la estabilidad laboral, el corto tiempo de actividad deportiva y la especialidad en la materia que generaría soluciones prontas y oportunas.

Al igual que lo anterior, también es legítimo en el reconocimiento de autonomía que el Estado le brinda a la justicia deportiva, una vez regularizada la situación jurídica de los clubes y federaciones ante las instancias de control dispuestas para el efecto.

De la misma manera, tanto la justicia deportiva de naturaleza privada, así como la justicia ordinaria administrada por el poder judicial del Estado, ejerce jurisdicción al conocer los conflictos de naturaleza laboral que emanen de la práctica profesional del fútbol, legitimado en el reconocimiento mutuo que mediante la normativa especial se perfecciona y la voluntad de los interesados de someter la controversia a cualquiera de los dos sistemas.

Esta opción que manejan las partes no entran en conflicto con la normativa deportiva, lo que no sucede con la Ley del Futbolista del Ecuador, específicamente en su artículo 37, que ha sido fundamento "suficiente" para que en algunos casos los jueces se inhiban de conocer los casos por incompetencia o lo mencionen como prerrequisito para acceder a la justicia ordinaria, en razón de la deficiente redacción e interpretación del mencionado artículo que prevé como una suerte de instancia previa a la justicia ordinaria al Tribunal Arbitral Especial de la FEF, cuando exige que las controversias en materia laboral deben 
ser resueltas por esta instancia para poder acceder a la justicia ordinaria, por lo que es necesaria la reforma de la citada norma abriendo la posibilidad de que tanto la Justicia Deportiva como la Ordinaria puedan ser las competentes para resolver la controversia según la voluntad de los interesados.

\section{REFERENCIAS BIBLIOGRÁFICAS}

Acosta, R. (2005). Gestión y Administración de las Organizaciones Deportivas. Primera Edición. Barcelona, España. Editorial Paidotribo.

Balbín, A. (2015). Revista Anales de la Facultad de Ciencias Jurídicas y Sociales de la U.N.L.P. El concepto de derecho de trabajo. 360. Recuperado de: http://sedici.unlp.edu.ar/bitstream/handle/10915/50671/ Documento_completo.pdf?sequence=1

Blanco, E. (2006). Manual de la Organización Institucional del Deporte. Primera Edición. Barcelona, España. Editorial Paidotribo.

Cabanellas, G. (2008). Diccionario Jurídico Elemental. Buenos Aires, Argentina: Heliasta.

Carta Olímpica (2016). Recuperado de: http://coe.org.ec/index.php/ organizacion/171-documentos/123-carta-olimpica-vigente

Cisneros, M. B. (2007). Derecho del Trabajo. México. Oxford University Press.

Congreso Nacional del Ecuador (1994). Ley del Futbolista Profesional. [Ley 56 de 1994]. RO: Suplemento 462.

Congreso Nacional del Ecuador (2005). Código del Trabajo. [Codificación 17 de 2005]. RO: Suplemento 167.

Congreso Nacional del Ecuador.( 2006). Ley de Arbitraje y Mediación. [Codificación 14 de 2006]. RO: Suplemento 417.

Congreso Nacional del Ecuador (1994). Ley del Futbolista Profesional. [Ley 56 de 1994]. RO: Suplemento 462. 
Congreso Nacional del Ecuador (2005). Código del Trabajo. RO: Suplemento 167.

Congreso Nacional del Ecuador (2006). Ley de Arbitraje y Mediación. [Codificación 14 de 2006]. RO: Suplemento 417.

Constitución de la República del Ecuador (Const). (2008). Registro oficial 449

Dávalos, J. (2016). El Derecho del Trabajo. Recuperado de: https:// archivos.juridicas.unam.mx/www/bjv/libros/9/4458/7.pdf

Echeverría, M. (2010). La Corte Arbitral de Deportes (TASCAS) como mecanismo moderno para la resolución de disputas en el fútbol profesional. Recuperado de: http://revistas.pucp.edu.pe/index.php/ forojuridico/article/view/18578/18818

Estatuto de la FIFA. (2016). Recuperado de: https://img.fifa.com/ image/upload/h6umsppqkszgedxmo1be.pdf

Gladstone, A. (1988). El Arbitraje voluntario de los conflictos de intereses. Suiza: Organización Internacional del Trabajo

Gladstone, A. (1988). El Arbitraje voluntario de los conflictos de intereses. Suiza: Organización Internacional del Trabajo

Graham, J., Sánchez, D. (2014). El Derecho Internacional del Fútbol. Segunda Edición. Monterrey, México. Zamanga, Editorial.

Mestre, J., Brotóns, J., Manzano, M. (2002). La gestión deportiva: clubes y federaciones. Primera Edición. Barcelona, España. INDE Publicaciones.

Monroy, A. y Sáenz, G. (2010). Estructura y Organización del Deporte en España. Primera Edición. Sevilla, España. Wanceulen Editorial Deportiva.

Reglamento del Estatuto y la transferencia de jugadores (2018). Recuperado de: https://resources.fifa.com/mm/document/affederation/administration/02/70/95/52/regulationsonthestatusandtransferofplayersjune2016_s_spanish.pdf 
Rosero, N. (2017). Arbitraje Deportivo: Experiencia del Tribunal Arbitral Du Sport. Recuperado de: http://revistas.pucp.edu.pe/index.php/ themis/article/view/19811

Recibido: 19 de julio de 2018

Aceptado: 4 de noviembre de 2018

Favio Andrés Velasco Guevara: Investigador Jurídico, Consejo de Educación Superior (CES)

Correo electrónico: faviovelascoguevara@gmail.com 